\title{
Exploring trends in admissions and treatment for ankle fractures: a longitudinal cohort study of routinely collected hospital data in England
}

Lauren J. Scott ${ }^{1,2^{*}}$ (D) Tim Jones ${ }^{1,2}$, Michael R. Whitehouse ${ }^{3,4,5}$, Peter W. Robinson ${ }^{5}$ and William Hollingworth ${ }^{1,2}$

\begin{abstract}
Background: Evidence on the most effective and cost-effective management of ankle fractures is sparse but evolving. A recent large RCT in older patients with unstable fractures found that management with close-contactcasting was functionally equivalent and more cost-effective than internal fixation. We describe temporal and geographic variation in ankle fracture management and estimate the potential savings if close-contact-casting was used more often in older patients.

Methods: Patients admitted to hospital in England between 2007/08 and 2016/17 with an ankle fracture were identified using routine hospital episode statistics. We tested whether the use of internal fixation, and the proportion of internal fixations using intramedullary implants, changed over time. We estimated the potential annual cost savings if patients aged 60+ years were treated with close-contact-casting rather than internal fixation, in line with emerging evidence.

Results: Over the 10-year period, there were 223,465 hospital admissions with a primary ankle fracture diagnosis. The incidence (per 100,000) of internal fixation was fairly consistent over time in younger (33.2 in 2007/08, 30.9 in 2016/17) and older (36.5 in 2007/08, 37.4 in 2016/17) patients. The proportion of internal fixations which used intramedullary implants increased in both age groups (17.0-19.5\% < 60 years; 15.2-17.4\% 60+ years). In 2016/17, the cost of inpatient hospital care for ankle fractures in England was over $£ 63.1$ million. If $50 \%$ of older patients who had an internal fixation instead had close-contact-casting, we estimate that approximately $£ 1.56$ million could have been saved.

Conclusions: Despite emerging evidence that non-surgical and surgical management achieve equivalent functional outcomes in older patients, the rate of surgical fixation has remained relatively stable over the decade. The health service could achieve substantial savings if a higher proportion of older patients were treated with close-contactcasting, in line with recent evidence.
\end{abstract}

Keywords: Ankle fracture, Hospital admission, England, Intramedullary fixation, Extramedullary fixation, Closecontact-casting

\footnotetext{
* Correspondence: Lauren.Scott@Bristol.ac.uk

${ }^{1}$ NIHR ARC West, University Hospitals Bristol and Weston NHS Foundation Trust, 9th Floor Whitefriars, Lewins Mead, Bristol BS1 2NT, UK

${ }^{2}$ Department of Population Health Sciences, Bristol Medical School, University of Bristol, Bristol BS8 2PS, UK

Full list of author information is available at the end of the article
}

(C) The Author(s). 2020 Open Access This article is licensed under a Creative Commons Attribution 4.0 International License, which permits use, sharing, adaptation, distribution and reproduction in any medium or format, as long as you give appropriate credit to the original author(s) and the source, provide a link to the Creative Commons licence, and indicate if changes were made. The images or other third party material in this article are included in the article's Creative Commons licence, unless indicated otherwise in a credit line to the material. If material is not included in the article's Creative Commons licence and your intended use is not permitted by statutory regulation or exceeds the permitted use, you will need to obtain permission directly from the copyright holder. To view a copy of this licence, visit http://creativecommons.org/licenses/by/4.0/ The Creative Commons Public Domain Dedication waiver (http://creativecommons.org/publicdomain/zero/1.0/) applies to the data made available in this article, unless otherwise stated in a credit line to the data. 


\section{Background}

Ankle fractures are increasingly common in the UK [1]. Trauma and frailty both play a role in the aetiology, with peaks in younger men and older women [1, 2]. As costs of fractures are high [3], it is important to identify and implement cost-effective care and to reduce variation in the care delivered.

In 2012, a systematic review [4] concluded there was insufficient evidence regarding the appropriateness of surgery versus conservative treatment of ankle fractures. Subsequently, two randomised controlled trials (RCTs) $[5,6]$ in younger adults with lateral malleolus fractures reported equivalent functional outcomes following internal surgical fixation versus non-surgical (cast or brace [6], boot [5]) treatment at 12-months. Participants in the surgical group spent longer in hospital and had more minor adverse events [5], however, delayed bone union was more common in the non-surgical group [6]. In older patients with unstable ankle fractures, a large RCT comparing internal fixation versus close-contact-casting reported equivalent ankle function at 6-months [7]. Infections and additional procedures were more common in the surgical group (10\% vs. 1 and $6 \%$ vs. $1 \%$, respectively), although $19 \%$ of patients initially treated with casts later had surgery. A higher rate of malunion and non-union of the medial malleolus was observed at long-term follow-up in the close-contact-cast group but this did not affect functional outcomes which remained equivalent at 3 years $[7,8]$. Close-contact-casting resulted in high initial and modest long-term cost savings and had a high probability of being cost-effective [9].

Small trials have evaluated the role of intramedullary implants compared to extramedullary fixation for lateral malleolar [10], bimalleolar or trimalleolar fractures [11, 12]. These trials indicate similar $[10,12]$ or better [11] functional outcomes in the intramedullary groups with fewer complications [10-12], which may offset the higher initial cost of the implant [10].

The 2016 British Orthopaedic Association Standards for Trauma and Orthopaedics (BOAST) 12 guidelines recommend early surgical fixation for unstable ankle fractures in patients < 60 years, and suggest closecontact-casting may be an option in patients over 60 years [13]. Close-contact-casting is applied in an operating theatre under general or spinal anaesthetic by an orthopaedic surgeon. This differs from a standard plaster cast which can be applied without anaesthetic in an outpatient environment [7].

\section{Aims}

To describe age, sex, temporal and geographic variation in ankle fracture admissions and management in England using routine Hospital Episode Statistics data. We estimated the costs of these admissions and discuss the potential impact of adopting recent evidence into clinical practice on those costs.

\section{Patients and methods \\ Data source}

Ankle fractures were identified from hospital episode statistics (HES) admitted patient care data. HES records all patient care episodes funded by the NHS $[14,15]$. An episode is defined as a period of care under one consultant team; therefore, a hospital admission may contain multiple episodes. International Classification of Diseases version 10 (ICD10) codes are used to record a primary and up to 19 additional diagnoses. Up to 24 procedures (Office of Population, Censuses and Surveys [OPCS] procedure codes) and demographic data including patient sex, age and area of residence are recorded for each episode. HES data is primarily collected for administrative purposes, including hospital reimbursement, but is often used for research. This study included adults (aged 16+ years) admitted between 1st April 2007 and 31st March 2017. We restricted our analyses to patients with inpatient admissions to hospital, as diagnoses are poorly recorded in emergency and outpatient department HES datasets.

\section{Identifying index admission and readmission of ankle fractures}

Patients with diagnosis codes of 'fracture of medial malleolus' (S825), 'fracture of lateral malleolus' (S826) or 'fracture of other parts of lower leg' (S828) as their primary diagnosis on their first episode within an admission were included (Fig. 1). The diagnosis code S828 primarily includes bimalleolar, trimalleolar and Maisonneuve's fractures, but may also include a small number of pilon (periarticular) fractures [16].

An index admission was defined as the first ankle fracture admission during the study period for a given patient, or an admission which occurred more than 365 days after a previous index admission for the same patient. A readmission was defined as a new ankle fracture admission which occurred 1-365 days following an index admission. Surgeons will sometimes discharge a patient to allow soft tissue swelling to go down and then readmit them, typically within 2-3 weeks, to perform surgery. As such, for this study, readmissions which occurred within 3 weeks of the index admission were assumed to be planned.

\section{Defining fracture management}

Procedure codes were used to define fracture management categories: intramedullary; extramedullary; internal (unspecified); external; and no surgical fixation (supplementary material 1 ). If more than one surgical fixation occurred within an admission, the first 


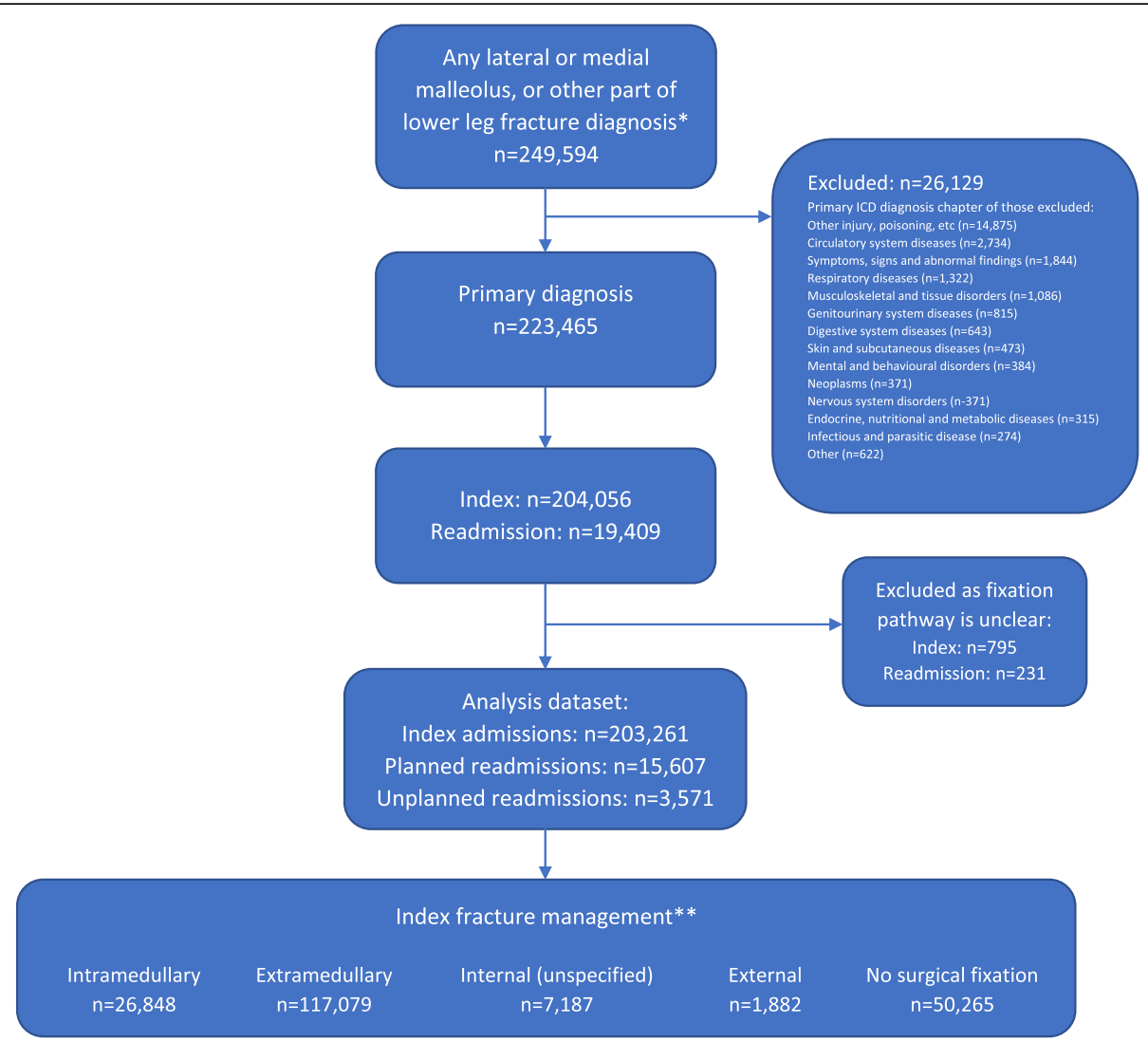

Fig. 1 Patient flowchart. *Patients with primary diagnoses of fractures of the lower end of tibia $(S 823 ; n=49,478)$, fibular alone $(S 824 ; n=32,609)$, and lower leg part unspecified $(5829 ; n=730)$ were not considered for this analysis as codes were not sufficiently specific. ${ }^{* *} 1560$ intramedullary, 6941 extramedullary, 500 internal (unspecified), and 112 external fixations occurred during planned readmissions in patients who had no surgical fixation on their index admissions

recorded fixation was used to categorise; the exception to this was if someone had an external fixator followed by an internal fixation, then the first internal fixation was used to categorise. As initial non-surgical stabilisation may be followed by planned surgery (as described above), we chose to categorise patients with no surgical fixation on the index admission, but surgical fixation on a readmission within 3 weeks, according to the first surgical fixation received during readmission (Fig. 1). Index admissions and any corresponding readmissions were excluded from the cohort if the OPCS code recorded only adjustment or removal of hardware but there was no code documenting the original fixation (Fig. 1).

\section{Statistical analyses}

Patient demographics are presented as counts and percentages or medians and interquartile ranges (IQRs), as appropriate. Crude admission rates were based on populations from June in the corresponding year [17].

\section{Temporal trends}

We report the annual number of ankle fracture admissions stratified by age group (16-59 and $60+$ years). We tested whether the incidence rate of internal fixation changed over the study period in either age group using Poisson regression with a binary age term, a categorical year term and an age-by-year interaction term, with the population in England (of 16+ year olds) in the corresponding year and age group as the offset. To test whether the proportion of internal fixations using intramedullary implants, and the proportion of admission which were day cases, changed over time, we used chisquared tests for linear trend in each age group.

\section{Geographic variation}

Geographical comparisons were made based on the clinical commissioning group (CCG) in which the patient resided. CCGs are NHS bodies responsible for planning and commissioning health care services for their local area; populations vary in size, covering a median of approximately 250,000 people [17]. As some procedures 
are relatively rare, we combined the most recent 5 years of data (2012/13-2016/17) to provide more stable estimates of recent procedure rates. We estimated indirectly standardised rate ratios of (a) any surgical fixations and (b) intramedullary fixations, using the population in England in June 2016 as the reference population, adjusting for age (16-39 years, $40-59$ years, $60-79$ years and $80+$ years) and sex [18]. We plot these ratios by CCG (as a percentage of the national average) to evaluate geographic variation in care provided. We converted the indirectly standardised rate ratios to adjusted yearly rates by multiplying them by the crude fixation rate of the reference population [19].

\section{Treatment costs}

The cost to CCGs of inpatient care for ankle fractures, including index admissions and readmissions, were estimated for $2016 / 17$ by linking secondary usage service generated core spell healthcare resource group (HRG) codes for each admission in HES with the 2016/17 payment by results tariff [20, 21]. HRG codes are assigned to each health care spell (i.e. hospital admission) based on their expected resource use; the payment by results tariffs are updated every year to reflect the cost of these resources. Based on evidence that close-contact-casting instead of internal fixation might save approximately $£ 650$ per patient [9], we estimated the potential annual savings that might be achieved if arbitrary proportions $(25,50,75 \%)$ of patients aged $60+$ years treated with internal fixations were instead treated with close-contactcasting.

All statistical analyses were conducted using Stata/MP 15.1.Variations in procedure rates across England were mapped using ArcGIS ArcMap 10.5.1 for Desktop, Environmental Systems Research Institute, Inc., 2017; the University of Bristol hold an Advanced, Concurrent-use licence for ArcGIS software.

\section{Results}

\section{Study cohort}

Over the 10-year study period, 249,594 hospital admissions included an ankle fracture diagnosis; for 223,465 patients (89.5\%), this was the primary diagnosis. After exclusions where the fixation pathway was unclear, our analysis cohort included 203,261 index admissions, 15, 607 planned readmissions and 3571 unplanned readmissions (Fig. 1). Forty-two percent of the cohort were male and the median age was 52 years (IQR 35 to 68). Admissions included 52,914 (26\%) lateral malleolus fractures, 21,784 (11\%) medial malleolus fractures and 128,563 (63\%) bimalleolar/trimalleolar/Maisonneuve fractures (Table 1). There were 19,258 admissions for ankle fractures (46.3 per 100,000 people) in $2007 / 08$ and 19,842 $(44.4$ per 100,000$)$ in $2016 / 17$. Incidence rose steeply
Table 1 Demographics of all patients with an index admission $(n=203,261)$

\begin{tabular}{lll}
\hline & $\mathrm{n}$ & $\%$ \\
\hline Age group $^{\mathrm{a}}$ & & \\
16-39 years & 62,382 & $30.7 \%$ \\
40-59 years & 61,338 & $30.2 \%$ \\
60-79 years & 56,998 & $28.0 \%$ \\
80+ years & 22,530 & $11.1 \%$ \\
Sex & & \\
Male & 86,238 & $42.4 \%$ \\
Female & 117,012 & $57.6 \%$ \\
Fracture type & & \\
Lateral malleolus & 52,914 & $26.0 \%$ \\
$\quad$ Medial malleolus & 21,784 & $10.7 \%$ \\
Bi/tri malleolar or Maisonneuve's & 128,563 & $63.3 \%$ \\
\hline
\end{tabular}

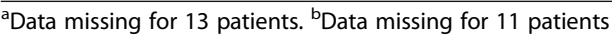

with age in females, with 27.3 and 120.8 per 100,000 women aged $16-39$ years and $80+$ years respectively in 2016/17; incidence in males was higher than females in $16-39$ year olds $(39.6$ per 100,000$)$ but remain reasonably stable with age (Table 2). Over the study period, the percentage of males decreased from $45 \%$ in $2007 / 08$ to $40 \%$ in 2016/17, and the median age of patients increased from 50 years (IQR 33 to 67) in 2007/08 to 54 years (IQR 36 to 69) in 2016/17.

\section{Fracture management}

Management differed by age (Fig. 2). Surgical fixation was far more common in $16-59$ year olds $(85 \%)$ than 80+ year olds (35\%). Extramedullary fixations occurred more often than intramedullary fixations in all age groups. The incidence of internal fixation of ankle fractures changed a little over time in both age groups (1659 and $60+$ years), with an increase between 2007/08 and 2009/10 and a generally decreasing trend from 2009/10 onwards (Fig. 3). The proportion of internal fixations using intramedullary implants increased over the study period in both younger (chi2 test for trend 76.2, $p<0.001$ ) and older (chi2 test for trend 59.7, $\mathrm{p}<0.001$ ) patients, although these changes were relatively small (Fig. 4). The proportion of admissions managed as day cases increased over the study period in both younger (chi2 test for trend 953.3, $\mathrm{p}<0.001$ ) and older (chi2 test for trend 111.7, $\mathrm{p}<0.001$ ) patients (Fig. 5); this increase was greater in younger patients $(6.3 \%$ in $2007 / 08$ compared to $14.2 \%$ in $2016 / 17$ ) than older patients (4.6\% in $2007 / 08$ compared to $7.7 \%$ in $2016 / 17$ ).

\section{Geographical variation}

After standardising for age and sex, the median yearly incidence rate of surgical fixation across all CCGs was 
Table 2 Incidence of admissions for ankle fractures in 2016/17 by age and sex

\begin{tabular}{|c|c|c|c|c|c|c|}
\hline \multirow[b]{2}{*}{ Age group } & \multicolumn{2}{|l|}{ Male } & \multicolumn{2}{|l|}{ Female } & \multicolumn{2}{|l|}{ Overall } \\
\hline & $n$ & n per 100,000 people & $n$ & n per 100,000 people & $n$ & n per 100,000 people \\
\hline 16-39 years & 3452 & 39.6 & 2331 & 27.3 & 5784 & 33.5 \\
\hline 40-59 years & 2436 & 33.6 & 3499 & 47.2 & 5935 & 40.5 \\
\hline 60-79 years & 1593 & 32.7 & 4119 & 78.2 & 5712 & 56.3 \\
\hline $80+$ years & 450 & 42.6 & 1955 & 120.8 & 2405 & 90.0 \\
\hline Overall & 7933 & 36.2 & 11,908 & 52.2 & 19,842 & 44.4 \\
\hline
\end{tabular}

Note. One person was missing sex data and six people were missing age data and as such are missing from the age/sex specific numbers. However, they are included in the overall numbers where possible, so column and row totals do not quite add up

34.0 per 100,000 people. Figure 6 a shows little variation in surgical fixation rates between CCGs across England; incidence in the CCG at the 90th percentile (41.1 per 100,000 ) was approximately $53 \%$ higher (rate ratio [RR] $1.53,95 \%$ confidence interval [19] [CI] 1.30 to 1.78 ) than the CCG at the 10th percentile (26.9 per 100,000). Intramedullary fixations had relatively larger variation between CCGs (Fig. 6b) with a median of 5.8 per 100,000 people and incidence in the CCG at the 90th percentile $(10.9$ per 100,000$)$ approximately 3.6 times higher (RR $3.55,95 \%$ CI 2.59 to 4.88 ) than the CCG at the 10th percentile (3.1 per 100,000).

\section{Readmissions}

Unplanned readmissions occurred following 3217/203, 261 (1.6\%) index admissions, with 3571 unplanned readmissions in total. This included $1.2 \%(309 / 26,848)$ of intramedullary fixations, $1.0 \%(1151 / 117,079)$ of extramedullary fixations and $2.9 \%(1461 / 50,265)$ of index visits with no surgical fixation. Only 31 (0.1\%) intramedullary and $137(0.1 \%)$ extramedullary fixations required readmission for removal. Supplementary material 2 details all fracture management which occurred during these unplanned readmissions. There were also a further 15,607 planned readmissions in 14,628 patients.

\section{Treatment costs}

In 2016/17, the cost to CCGs of inpatient hospital care for ankle fractures in England was more than E63.1million; this included $£ 33.8$ million and $£ 19.7$ million spent on internal fixations in patients $16-59$ and $60+$ years old, respectively. The median cost of care was $£ 3034$ (IQR $£ 1969$ to $£ 4084$ ) for internal fixations and $£ 1016$ (IQR $£ 557$ to $£ 1819)$ for no surgical fixation. If $25,50 \%$ or $75 \%$ of older patients (60+ years) who had an internal fixation in 2016/ $17(n=4787)$ instead had close-contact-casting, we estimate that CCGs could have saved approximately $£ 778$,

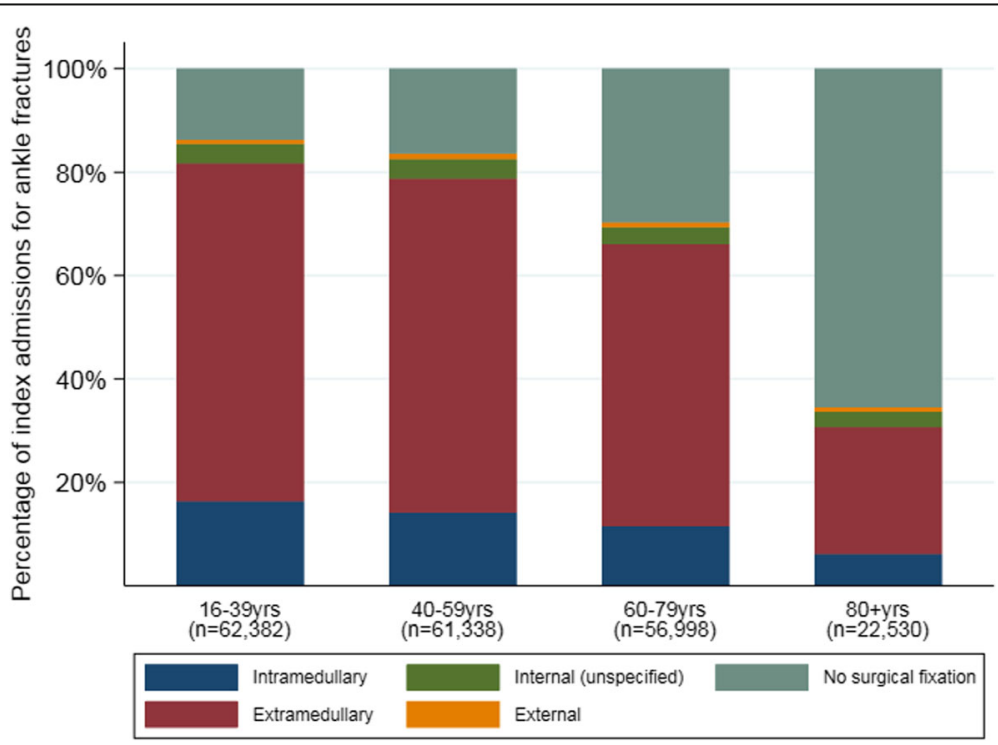

Fig. 2 Fracture management by age 
(a)

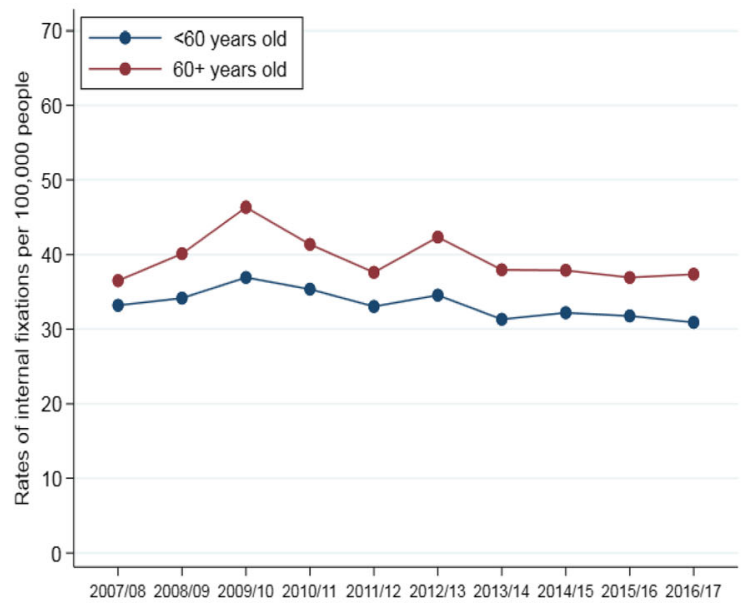

(b)

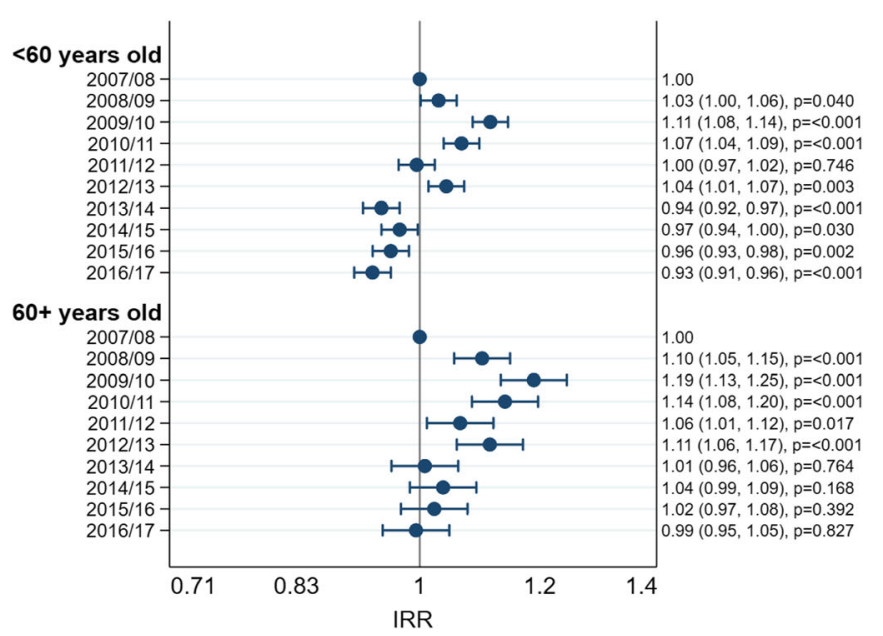

Fig. 3 Internal fixations over time by age group. a Rates per 100,000 people, b Incidence rate ratios (IRRs) from Poisson regression

000 , $£ 1.56$ million, or $£ 2.33$ million respectively (assuming a saving to the NHS of $£ 650$ per patient [9]).

\section{Discussion}

\section{Summary of findings}

In 2016/17, nearly 20,000 people in England were admitted for management of ankle fractures at a cost of approximately $£ 63.1$ million to CCGs. Incidence of ankle fractures and surgical management varied substantially by age. Despite emerging evidence that non-surgical and surgical management may achieve equivalent functional outcomes at 3 -years in patients over 60 with unstable ankle fractures, the rate of surgical fixation has remained relatively stable over the decade. The health service could achieve substantial savings, at least in the short term, if a higher proportion of older patients were treated with close-contact-casting, in line with recent evidence. An increasing proportion of patients who underwent surgical fixation had intramedullary implants, although evidence that this approach is more costeffective than extramedullary fixation or non-surgical management is insufficient.

\section{Strengths and limitations}

We believe this is the first paper exploring ankle fracture management using routinely collected data covering the

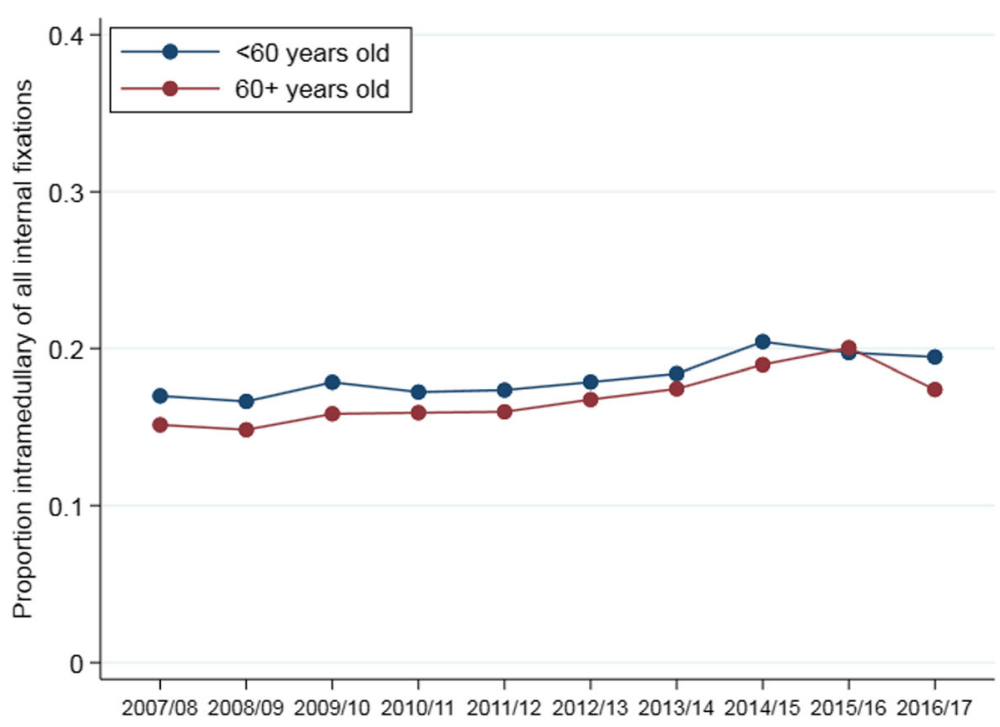

Fig. 4 Proportion of internal fixations which are intramedullary over time by age group 


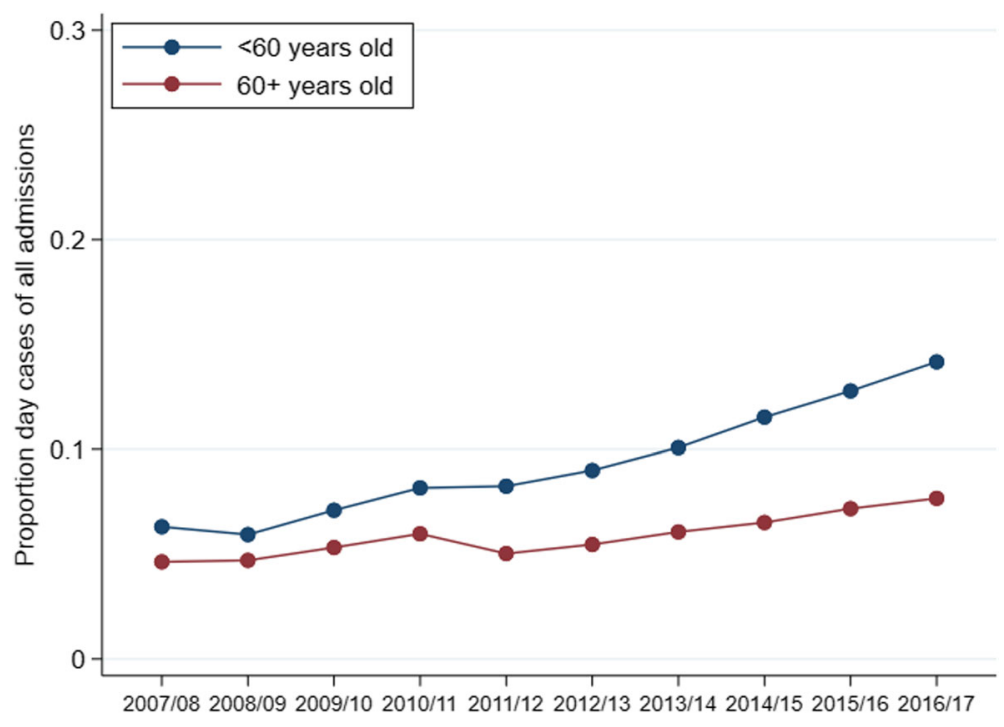

Fig. 5 Proportion of admissions which are day cases over time by age group

whole of England. This enabled us to analyse many patients over an extended period. Hospital reimbursement is based on the diagnosis and procedure codes recorded in HES, therefore there are incentives for these data to be comprehensively recorded. However, this is routine data so will inevitably contain data entry errors; for example, an audit between 2010 and 2013 found that 13\% of primary diagnoses and $12 \%$ of primary procedures were coded incorrectly [22]. Our analysis only includes patients admitted to hospital so we cannot determine (a)
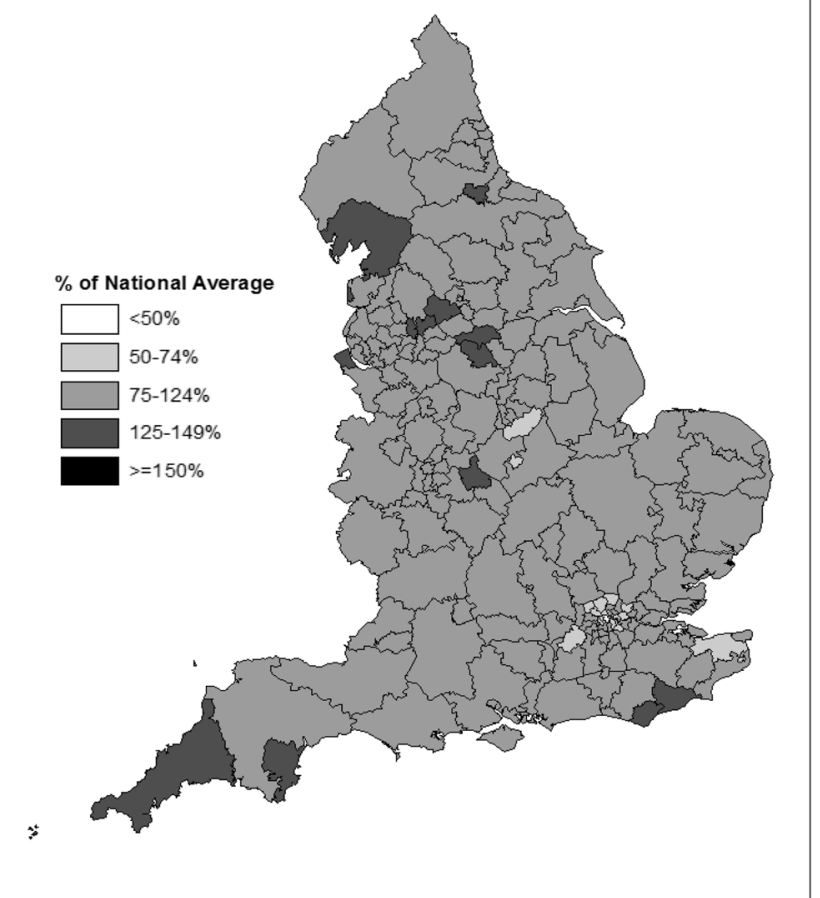

(b)

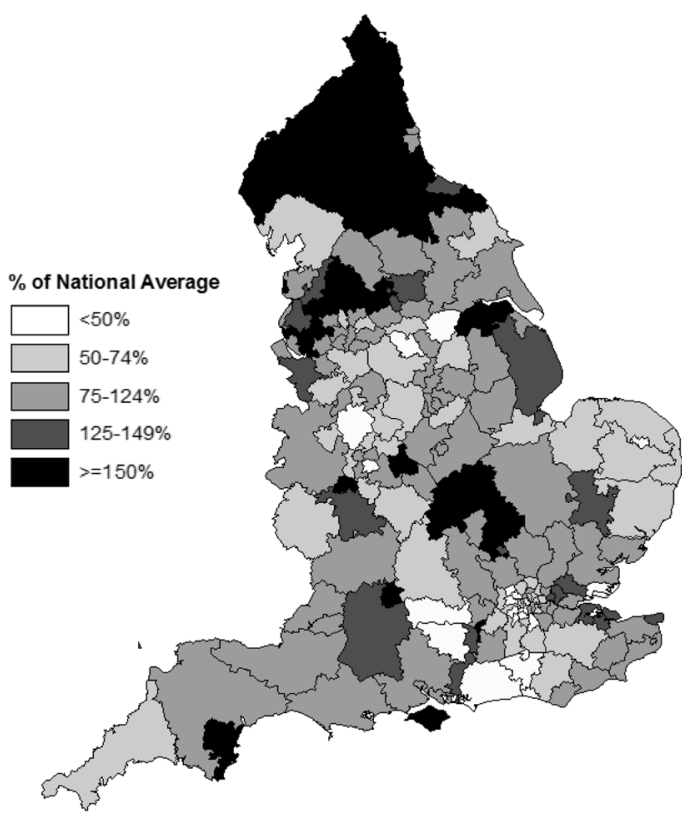

s

Fig. 6 Geographical variation of surgical fixations. a Any surgical fixation, b Intramedullary fixations. Figures show indirectly standardised rate ratios and include data from 2012/13-2016/17. These figures were created using ArcMap software with the University of Bristol's advanced, concurrent-use licence for ArcGis software (see methods for details) 
the incidence of ankle fractures managed non-surgically in the emergency department or in outpatient appointments. We also cannot distinguish between stable and unstable fractures, typically determined by analysis of radiographs or clinical assessment. We excluded non-specific lower limb fracture diagnosis codes and admissions where ankle fracture was a secondary diagnosis, so our estimates are conservative. The inclusion of the primary diagnostic code S828 would also include some more complex periarticular fractures, but the proportion of these is low and therefore not expected to affect our results [16]. Similarly, lateral malleolus avulsion fractures may be included but again numbers are expected to be small as patients wouldn't often be admitted for such fractures (and if they were, it would primarily be for social care reasons). Although procedure codes allowed us to distinguish broad categories of management, they were not specific enough to differentiate types of intramedullary nail, such as fibular or tibio-talo-calcaneal nails, or methods of non-surgical management (e.g. cast or boot). The HES pseudonymised patient identifiers make it possible to identify readmissions, however they did not distinguish whether it was for management of the original or a new fracture or for a planned or unplanned event, therefore we inferred this based on timing.

\section{Comparisons to other literature}

Based on analysis of UK primary care records, the annual incidence of ankle fracture is estimated to be 75 per 100 , 000 adults $<50$ years and 104 per 100,000 50+ year olds [2]. The incidence rate in our study (44 per 100,000 adults in 2016/17) was lower, suggesting that many ankle fractures are managed in emergency and outpatient care. In Sweden (1987-2004), the incidence of hospitalisation for ankle fracture among all adults was estimated at 75 per 100,000 [23], while in Finland (1997-2006) 144 of 100,000 adults age $60+$ years were hospitalised [24]. The lower rates observed in our study might be due to decreasing trends for hospitalisation in recent years, although this hypothesis is not supported by our data. Other potential explanations include differences between countries in risk factors and incidence or differences in clinician thresholds for admitting patients to hospital. Our finding that bimalleolar and trimalleolar fractures account for a substantial proportion of patients hospitalised with ankle fractures is in line with previous studies $[23,25]$. The 365-day readmission rate for ankle fracture among patients with extramedullary fixations $(1.0 \%)$ is lower than the previously reported all cause 30 -day readmission rates (3.2\%) among similar patients in the US [26].

Geographical variations in procedure rates are likely to be highest in areas of medicine where clinicians differ in their belief about the value of the procedure [27, 28]. Based on US Medicare data on patients aged 65+ years, Koval et al. [29] observed that surgical stabilisation of ankle fractures ranged from 14 to $72 \%$ across different areas of the country. We observed little geographic variation in surgical fixation rates, after adjusting for age and sex. We do not know what the 'right' rate of surgical fixation is, but recent evidence that close-contact-casting is more cost-effective than surgical fixation in older patients [9] indicates that reducing rates may lead to more efficient care. Results of this RCT have been reported at 3-years [8] but longer-term follow-up may be required.

\section{Implications for research and clinical practice}

The evidence supporting surgical and non-surgical treatments of ankle fractures is relatively weak and is predominantly based on observational studies and small RCTs. The evaluation of surgical innovations provides unique challenges [30], but large wellconducted pragmatic trials are possible. In ankle fractures, the AIM trial [7-9] and recently initiated FAME trial [31], have the potential to provide more definitive answers to improve practice. Our data largely pre-date the publication of the AIM trial results; nevertheless, we did not observe any large decrease in surgical fixation rates among older patients during the trial or immediately after publication. In contrast, the DRAFFT trial demonstrating that Kirschner(K)-wires were more cost-effective than plate fixation for the management of distal radius fractures, was associated with a dramatic shift towards K-wire fixation [32]. Implementation of one surgical approach instead of another may be a simpler message to disseminate than a move from surgical to nonsurgical management.

Guidelines listing close-contact-casting as a treatment option may not, in isolation, be enough to disseminate the findings of the AIM trial and reduce rates of surgical fixation in older patients. More proactive options such as CCG criteria-based access policies which define the patient subgroups where surgery will be funded, or shared decision-making tools to provide patients with a greater role in the decision making, may lead to greater changes in care delivery [33]. Our data suggest that the savings of a switch towards non-surgical care in only $25 \%$ of older patients currently treated with internal fixations would be relatively modest ( $£ 778,000$ per year), but would accumulate if sustained over time or generalised a greater proportion of patients or to other countries.

We observed small increases in the proportion of surgical fixation performed with intramedullary implants. Although intramedullary implants use smaller incisions that reduce soft tissue disruption and may allow early weight bearing, better evidence from larger trials is needed to determine their long-term cost-effectiveness [34]. 


\section{Conclusion}

We found relatively stable rates of surgical fixation for ankle fractures despite emerging evidence that nonsurgical and surgical management achieve equivalent long-term functional outcomes in older patients. Effective implementation of robust randomised trial findings with sufficient length of follow-up is needed to improve patient care and reduce health system costs.

\section{Supplementary information}

Supplementary information accompanies this paper at https://doi.org/10. 1186/s12913-020-05682-9.

Additional file 1. Supplementary material 1. Identifying procedures for ankle fractures.

Additional file 2. Supplementary material 2. Fracture management during unplanned readmissions.

\section{Abbreviations \\ BOAST: British Orthopaedic Association Standards for Trauma and Orthopaedics; CCG: Clinical Commissioning Group; HES: Hospital Episode Statistics; HRG: Health Resource Group; ICD10: International Classification of Diseases version 10; NHS: National Health Service; OPCS: Office of Population, Censuses and Surveys; RCT: Randomised Controlled Trial; UK: United Kingdom}

\section{Acknowledgements}

The authors would like to thank NHS Digital who provided the Hospital Episode Statistics admitted patient care data; copyright@ 2019, re-used with the permission of the Health and Social Care Information Centre ("NHS Digital"). All rights reserved.

\section{Authors' contributions}

This publication is the work of all authors. LS contributed to study design, data cleaning, data analysis, interpretation of results and writing the manuscript. TJ, WH, MW and PR contributed to study design, interpretation of results and writing the manuscript. All authors have read and approved the final manuscript.

\section{Funding}

This research was funded by the National Institute for Health Research (NIHR) Applied Research Collaboration West (NIHR ARC West) at University Hospitals Bristol and Weston NHS Foundation Trust and supported by the NIHR Biomedical Research Centre at University Hospitals Bristol and Weston NHS Foundation Trust. The funder had no role in the conduct or reporting of the study. The views expressed are those of the authors and not necessarily those of NHS England, NHS Improvement, the NIHR or the Department of Health and Social Care.

\section{Availability of data and materials}

The data in this study were provided by patients and collected by the NHS as part of their care and support. HES data can be accessed via NHS Digital: https://digital.nhs.uk/services/data-accessrequest-service-dars.

\section{Ethics approval and consent to participate}

We were provided with routinely collected Hospital Episode Statistics data under licence from NHS Digital (DARS-NIC-17875-X7K1V). The licence allows us to use the information under Section 261 of the Health and Social Care Act 2012, 2(b)(ii): "after taking into account the public interest as well as the interests of the relevant person, considers that it is appropriate for the information to be disseminated".

\section{Consent for publication}

Not applicable.

\section{Competing interests}

The authors declare that they have no competing interests.

\section{Author details}

${ }^{1} \mathrm{NIHR}$ ARC West, University Hospitals Bristol and Weston NHS Foundation Trust, 9th Floor Whitefriars, Lewins Mead, Bristol BS1 2NT, UK. ²Department of Population Health Sciences, Bristol Medical School, University of Bristol, Bristol BS8 2PS, UK. ${ }^{3}$ Musculoskeletal Research Unit, Translational Health Sciences, Bristol Medical School, 1st Floor Learning \& Research Building, Southmead Hospital, Bristol BS10 5NB, UK. ${ }^{4}$ National Institute for Health Research Bristol Biomedical Research Centre, University Hospitals Bristol and Weston NHS Foundation Trust and University of Bristol, Bristol, UK. ${ }^{5}$ Avon Orthopaedic Centre, Southmead Hospital, North Bristol NHS Trust, Westbury-on-Trym, Bristol BS10 5NB, UK.

Received: 12 February 2020 Accepted: 23 August 2020 Published online: 31 August 2020

\section{References}

1. van der Velde RY, Wyers CE, Curtis EM, et al. Secular trends in fracture incidence in the UK between 1990 and 2012. Osteoporos Int. 2016;27(11): 3197-206.

2. Curtis EM, van der Velde R, Moon RJ, et al. Epidemiology of fractures in the United Kingdom 1988-2012: variation with age, sex, geography, ethnicity and socioeconomic status. Bone. 2016;87:19-26.

3. Bielska IA, Wang $X$, Lee $R$, et al. The health economics of ankle and foot sprains and fractures: A systematic review of English-language published papers. Part 2: The direct and indirect costs of injury. Foot (Edinb). 2019;39: 115-21.

4. Donken CC, Al-Khateeb $\mathrm{H}$, Verhofstad $\mathrm{MH}$, et al. Surgical versus conservative interventions for treating ankle fractures in adults. Cochrane Database Syst Rev. 2012;8:CD008470.

5. Mittal R, Harris IA, Adie $S$, et al. Surgery for type B ankle fracture treatment: a combined randomised and observational study (CROSSBAT). BMJ Open. 2017;7(3):e013298

6. Sanders DW, Tieszer C, Corbett B, et al. Operative versus nonoperative treatment of unstable lateral malleolar fractures: a randomized multicenter trial. J Orthop Trauma. 2012;26(3):129-34.

7. Willett $K$, Keene DJ, Mistry D, et al. Close contact casting vs surgery for initial treatment of unstable ankle fractures in older adults: a randomized clinical trial. JAMA. 2016;316(14):1455-63.

8. Keene DJ, Lamb SE, Mistry D, et al. Three-year follow-up of a trial of close contact casting vs surgery for initial treatment of unstable ankle fractures in older adults. JAMA. 2018;319(12):1274-6.

9. Keene DJ, Mistry D, Nam J, et al. The ankle injury management (AIM) trial: a pragmatic, multicentre, equivalence randomised controlled trial and economic evaluation comparing close contact casting with open surgical reduction and internal fixation in the treatment of unstable ankle fractures in patients aged over 60 years. Health Technol Assess. 2016;20(75):1-158.

10. White TO, Bugler KE, Appleton $P$, et al. A prospective randomised controlled trial of the fibular nail versus standard open reduction and internal fixation for fixation of ankle fractures in elderly patients. Bone Joint J. 2016;98-B(9): 1248-52.

11. Asloum $Y$, Bedin $B$, Roger $T$, et al. Internal fixation of the fibula in ankle fractures: a prospective, randomized and comparative study: plating versus nailing. Orthop Traumatol Surg Res. 2014;100(4 Suppl):S255-9.

12. Georgiannos $D$, Lampridis $V$, Bisbinas I. Fragility fractures of the ankle in the elderly: open reduction and internal fixation versus tibio-talo-calcaneal nailing: short-term results of a prospective randomized-controlled study. Injury. 2017;48(2):519-24.

13. British Orthopaedic Association. BOA Standards for Trauma and Orthopaedics (BOAST) 12: The Management of Ankle Fractures. 2016.

14. Centre HSCl. Hospital episode statistics (HES) analysis guide; 2015.

15. Herbert A, Wijlaars L, Zylbersztejn A, et al. Data Resource Profile: Hospital Episode Statistics Admitted Patient Care (HES APC). Int J Epidemiol. 2017; 46(4):1093-i.

16. Court-Brown CM, Caesar B. Epidemiology of adult fractures: a review. Injury. 2006:37(8):691-7.

17. Office for National Statistics. Clinical commissioning group population estimates. [Available from: https://www.ons.gov.uk/ peoplepopulationandcommunity/populationandmigration/ populationestimates/datasets/ clinicalcommissioninggroupmidyearpopulationestimates]. 
18. Anon. Standardization: a classic epidemiological method for the comparison of rates. Epidemiol Bull. 2002;23(3):9-12.

19. Kirkwood B, Sterne A. Essential medical statistics. 2nd ed. Oxford: Blackwell Publishing Ltd; 2003.

20. Department of Health and Social Care. Statutory guidance: NHS National Tariff Payment System 2016/17. Annex A: 2016/17 national prices and national tariff workbook. [Available from https:/www.gov.uk/government/ publications/nhs-national-tariff-payment-system-201617].

21. Department of Health and Social Care. Statutory guidance: NHS National Tariff Payment System 2016/17. 2016/17 National Tariff Payment System. [Available from https://www.gov.uk/government/publications/nhs-nationaltariff-payment-system-201617].

22. Nouraei SA, Hudovsky A, Frampton AE, et al. A study of clinical coding accuracy in surgery: implications for the use of administrative big data for outcomes management. Ann Surg. 2015;261(6):1096-107.

23. Thur CK, Edgren G, Jansson KA, et al. Epidemiology of adult ankle fractures in Sweden between 1987 and 2004: a population-based study of 91,410 Swedish inpatients. Acta Orthop. 2012;83(3):276-81.

24. Kannus $\mathrm{P}$, Palvanen $\mathrm{M}$, Niemi $\mathrm{S}$, et al. Stabilizing incidence of low-trauma ankle fractures in elderly people Finnish statistics in 1970-2006 and prediction for the future. Bone. 2008:43(2):340-2.

25. Shibuya N, Davis ML, Jupiter DC. Epidemiology of foot and ankle fractures in the United States: an analysis of the National Trauma Data Bank (2007 to 2011). J Foot Ankle Surg. 2014;53(5):606-8.

26. Basques BA, Miller CP, Golinvaux NS, et al. Morbidity and readmission after open reduction and internal fixation of ankle fractures are associated with preoperative patient characteristics. Clin Orthop Relat Res. 2015;473(3):1133-9.

27. Birkmeyer JD, Reames BN, McCulloch P, et al. Understanding of regional variation in the use of surgery. Lancet. 2013;382(9898):1121-9.

28. Wennberg JE, Barnes BA, Zubkoff M. Professional uncertainty and the problem of supplier-induced demand. Soc Sci Med. 1982;16(7):811-24.

29. Koval KJ, Lurie J, Zhou W, et al. Ankle fractures in the elderly: what you get depends on where you live and who you see. J Orthop Trauma. 2005;19(9): 635-9.

30. Cook JA. The challenges faced in the design, conduct and analysis of surgical randomised controlled trials. Trials. 2009;10:9.

31. NIHR HTA. In younger adults with unstable ankle fractures treated with close contact casting, is ankle function not worse than those treated with surgical intervention? The FAME Trial. 2019 [Available from: https://www. journalslibrary.nihr.ac.uk/programmes/hta/NIHR127273/\#/.

32. Costa ML, Jameson SS, Reed MR. Do large pragmatic randomised trials change clinical practice?: assessing the impact of the distal radius acute fracture fixation trial (DRAFFT). Bone Joint J. 2016;98-B(3):410-3.

33. Hutchinson RH, Barrie JL. The effects of shared decision making in the conservative management of stable ankle fractures. Injury. 2015;46(6):1116-8.

34. Jordan RW, Chapman AWP, Buchanan D, et al. The role of intramedullary fixation in ankle fractures - a systematic review. Foot Ankle Surg. 2018;24(1): $1-10$.

\section{Publisher's Note}

Springer Nature remains neutral with regard to jurisdictional claims in published maps and institutional affiliations.

Ready to submit your research? Choose BMC and benefit from:
- fast, convenient online submission
- thorough peer review by experienced researchers in your field
- rapid publication on acceptance
- support for research data, including large and complex data types
- gold Open Access which fosters wider collaboration and increased citations
- maximum visibility for your research: over 100M website views per year
At BMC, research is always in progress.
Learn more biomedcentral.com/submissions

